Article

\title{
The Behavioral Pattern of Chinese Public Cultural Participation in Museums
}

\author{
Wende Wang ${ }^{1} \mathbb{D}$, Mozhuang $\mathrm{Fu}^{2}$ and Qingwu $\mathrm{Hu}^{3, * \mathbb{D}}$ \\ 1 National Institute of Cultural Development, Wuhan University, Wuhan 430072, China; \\ qimingxing@whu.edu.cn \\ 2 Department of Statistical Sciences, University of Toronto, Toronto, ON M5S 3G3, Canada; \\ mz970310@gmail.com \\ 3 School of Remote Sensing and Information Engineering, Wuhan University, Wuhan 430072, China \\ * Correspondence: huqw@whu.edu.cn
}

Received: 12 March 2020; Accepted: 3 April 2020; Published: 5 April 2020

\begin{abstract}
Studying the cultural participation model of the public and its influencing factors is important for the sustainable development of regional culture. Therefore, in this study, we determined which factors influence the cultural participation of the Chinese public. Firstly, we extracted the key features of the motivation and timing for a museum visit with multiple correspondence analysis (MCA), and explored the relationship of the features of different motivations with the frequency and duration of the public's visits to the museum. Secondly, we determined the monotonicity of the influence of ordinal variables on cultural participation behavior and identified the mechanism through which the independent variable influences public cultural participation with categorical regression (CATREG). Finally, we analyzed the research data from the museum audience survey in the Hubei Provincial Museum and a national public culture participation survey. We found that education, occupation, academic discipline, income, distance, age, and sex affect the public's museum participation. This indicates that to guarantee the public's cultural rights and promote sustainable development, education, planning, and other aspects must be coordinated in cultural management to increase public cultural participation, rather than removing the economic threshold for public cultural participation through public finances alone.
\end{abstract}

Keywords: cultural sustainability; cultural participation; cultural capital; cultural management; museum

\section{Introduction}

Development is a common theme in all countries and departments. Cultural sustainable development holds that there are three kinds of interactions between culture and sustainability, including that culture is the fourth pillar of sustainable development, culture mediates the development of social, environmental, and economic sustainability, and is regarded as a necessary overall foundation and structure for achieving sustainable development [1-3]. Culture plays an important role in promoting sustainable development. Cultural participation is significantly related to cultural sustainability [4], because the cultural education functions of the museums and other cultural departments are important to ensure the transmission and development of culture. It also improves individual cultural literacy and needs, which can promote the development of the cultural economy. Therefore, the study of cultural participation behavior has important significance for sustainable development.

Research on public cultural participation behavior is an integral part of western cultural economics and cultural management. Brida et al. found that education level has a positive impact on the public's repeated visits to museums, whereas the economic income level and distance from home to museums 
have a negative impact [5]. Ateca-Amestoy and Prieto-Rodriguez also found that sex influences the behavioral pattern of the public visiting museums, as do occupation and distance [6]. Kraaykamp et al. proved that people who live in urban centers visit museums more often than those who live in other areas, and people who spend more time in museums are less likely to visit again [7]. Brida et al. studied the factors and mechanisms influencing public museum visits from the perspective of visiting motivation, and found that cultural capital, occupation, sex, marriage, economic income, spatial relationship, and other factors all have an impact on the participants' frequency of visiting museums [8]. Van Hek and Kraaykamp studied how cultural preferences are transferred across generations [9], and Willekens et al. focused on the influence of the father and mother's educational level on teenagers' cultural participation motivation [10]. All of these studies are centered around cultural participation and study how the public's cultural participation behavior is affected.

Although existing research has provided a wealth of perspectives on public cultural participation behaviors, we found that the existing research on cultural participation mainly focuses on whether the public participates in cultural activities and services, and few scholars have examined the frequency of public cultural participation $[7,11]$. However, cultural participation is a behavioral activity characterized by multidimensional information [12], including whether the public participates and the frequency of participation as well as the motivation, duration, and timing, which are essential dimensions for describing cultural participation and provide a reference for identifying public cultural participation behavioral patterns. Exploring this information will help museums and other cultural institutions to scientifically plan their activities and schedules, which is beneficial to improving the cultural and educational effectiveness of public cultural services and promoting cultural sustainable development.

Besides, cultural differences result in different patterns of cultural participation in different regions, but research on the cultural participation of the Chinese public is lacking. Culture is a vibrant concept [13] defined as a set of inner beliefs and values that people may never express, but carry around in their heads [14]; as a set of publicly shared codes or repertoires that are essential to the ability to think of and share ideas [15]; as a distribution of things, way of life, meaning, and doing [16]; and so on. The culture referred to here focuses on the ideas, traditions, concepts, and behavioral norms shared by a group. Therefore, culture has an embedded effect on individual socialization. Although the development of the Internet has broken through the limitations of geographical areas, many studies still indicate that geographical areas significantly impact culture and behavior [17,18], because geographical regions significantly impact the generation of culture, and policy differences also shape cultural similarities in the region and cultural heterogeneity between regions. The academic community has exhibited many achievements in the field of cultural participation, but most studies examined individual countries or regions [19]. Although early Chinese scholars paid attention to the behavioral decisions of the museum audience, such as Chen [20] and Shan [21], research on cultural participation has not received enough attention. In recent years, through the positivism method, Chinese academic circles have conducted some investigations. Kang studied the visiting behavior of elderly visitors [22]. Lv et al. found that museum visitors appreciate exhibits with a large size, exquisite production, precise location, close connection with life, and peculiar expression techniques more, by surveying Hubei Provincial Museum [23]. Sheng and Chen analyzed the preference of tourists to visit [24]. Courty and Zhang studied the cultural consumption behavior of the Chinese public from a broad perspective in 13 major cities in China [19]. However, the research scope of the museum audience of China is relatively narrow and no systematic theoretical scheme of audience research has been formed [19,25]. In particular, a consensus has not yet been reached about the influence mechanism of the public's cultural participation behavior under the open for free cultural policy.

The open for free cultural policy is facing sustainable development issues. Before 2008, public cultural facilities in China provided paid cultural services to the public, which meant that the public had to pay for admission to the museum. The open for free cultural policy, which has been implemented since 2008, results in the number of visitors to museums increasing rapidly [26], indicating that the open for free cultural policy eliminated the negative impact of economic costs on public visits to 
museums. However, it has brought unprecedented issues to cultural sustainable development in recent years. Inadequate motivation, caused by a full financial guarantee, has become an essential issue for Chinese cultural governance. $\mathrm{Lu}$ and $\mathrm{Li}$ indicated that Chinese museums have been facing imbalances between supply and demand, meaning that the cultural services provided by the museum failed to meet the diverse cultural needs of the public [27]. Shan argued that the lack of museum audience research has prevented museum managers from understanding the public demand for museums and improving museum management [21]. Fu and colleagues demonstrated that the current national public cultural investment is facing diminishing marginal efficiency, mainly due to the lack of technical management and the congestion of resource allocation, which has led to sustainable development issues, such as imbalances between supply and demand [28-33]. Studying cultural participation behavioral patterns is conducive to optimizing public cultural policies aimed at promoting sustainable cultural development [32,33], and can guide national cultural policies based on the principle of the cultural exception. It motivates us to take Chinese public cultural participation in museums as a case for cultural participation research.

To enrich the dimension of cultural participation behavior research and expand the research practice of cultural participation behavior model in China to provide cultural management knowledge for the sustainable development issues faced by China's open for free cultural policy, we present how the behavioral pattern of cultural participation is affected, which includes whether the public choose to participate, motivation, frequency, duration, and timing, and take Chinese public cultural participation in the museum as a case to expand cultural participation in research practices in China in this paper. To explore the cultural participation behavioral pattern in museums of the Chinese public, a multi-dimensional analysis model of cultural participation was established in this study. The dependent variables of this model were whether to visit museums, motivation, frequency, duration, and timing, and the independent variables were education, academic discipline (except for whether to visit the museum), income, distance, age, sex, and occupation. Based on survey data of the public cultural participation of Chinese urban residents and the audience at the Hubei Provincial Museum, multiple correspondence analysis (MCA) was employed to extract key features of the public's motivation and timing of museum visits, and categorical regression (CATREG) was employed to explore the factors and mechanisms influencing cultural participation in Chinese public museums. Finally, from MCA, we found that cultural and functional aspects are the first two key features of motivation, and facilitation- and efficiency-based aspects are the first two key features influencing the timing of cultural participation at the museum. From CATREG, we found that education is the most important factor influencing whether the public visits museums, cultural motivation, and facilitation-based timing. Discipline, income, and distance were found to have a significant effect on public cultural participation at museums, as did sex and age. If the categorical variables are analyzed using an analytical model based on a linear hypothesis in the study of cultural participation, the strength of the impact of some categorical variables may be underestimated.

\section{Hypotheses}

Cultural capital impacts cultural participation, but the reported research results of different scholars vary. The cultural capital paradigm based on Bourdieu's cultural capital theory $[34,35]$ emphasizes the critical role of cultural capital in the public's cultural participation, including (1) the threshold effect hypothesis, which supports the argument that cultural capital is the most critical factor stimulating the public's motivation for cultural participation; and (2) the utility maximization hypothesis, which holds that the higher the individual's cultural capital, the greater the utility gained in cultural participation. There are three forms of cultural capital: objectified cultural capital referring to objects which require cultural abilities; institutionalized cultural capital referring to formal education credentials; embodied cultural capital referring the abilities to appreciate and understand cultural goods. We can assume that cultural capital has a positive role in promoting cultural participation by embodied cultural capital. Current research has measured cultural capital more from the perspective 
of formal education in schools, meaning that the embodied cultural capital is usually expressed by institutionalized cultural capital in cultural participation studies. It is generally thought that individuals with higher education levels have more cultural capital. However, the issue of disciplinary differentiation in the modern education system is indisputable, and disciplinary differences significantly impact individual experience and development [36]. Therefore, when measuring cultural capital from the perspective of formal education, the cultural capital differences caused by disciplinary differences must be considered. Due to the differences in subject knowledge systems, individuals with an artistic educational background generally have a greater artistic aesthetic ability than individuals with an engineering educational background; that is, they have high cultural capital. In addition to the individual perspective, the social relations generated by school education will also further strengthen the differences in the patterns of individual museum visit behaviors due to the peer effect. Therefore, we measured cultural capital from the perspective of education and discipline, and proposed the first hypothesis as follows.

Hypothesis 1 (H1). Cultural capital affects cultural participation.

Maslow's hierarchy of needs contains five levels: physiology, safety, society, self-esteem, and self-realization. The model states that the formation of high-level needs is generally based on the satisfaction of low-level needs [37]. In this study, public cultural participation was considered a process for individuals to fulfill social needs, self-esteem needs, and self-realization. The economic capital status of individuals is one of the underlying conditions of their culture that needs to be satisfied, playing a vital role in activating individual cultural needs. We also examined the impact of economic capital on individual cultural participation models. Ateca-Amestoy and Prieto-Rodriguez [6], Molinillo and Japutra [38], and Kim et al. [39] studied the impact mechanism of cultural participation from the perspective of individual income. Therefore, we measured economic capital based on individual monthly income, and proposed the second hypothesis as follows.

Hypothesis 2 (H2). Economic capital influences individual cultural participation.

Time cost describes both the travel and visiting time of cultural participation. The time cost is also an essential factor influencing the decision-making of the public's cultural participation, which is influenced by an individual's limited leisure time and time management concept. Kraaykamp et al. explored the impact of time cost on the frequency of cultural participation using data from a survey of a Dutch population and found that when both husband and wife had full-time jobs, the frequency of participation in high-level cultural activities was significantly lower than that of other families [7]. Travel and visiting times have different effects on individual cultural participation decision-making because attention profoundly affects time perception [40]. Based on this, we assumed that travel time is an additional time cost for cultural participation, with much greater influence than visiting time, which can also be understood as the spatial relationship between people and museums. Therefore, we used travel time as a measure of the time cost of an individual's visit to the museum and the relationship between the individual's habitual residence and the museum space, and proposed the third hypothesis as follows.

Hypothesis 3 (H3). Spatial relationships and time are two factors that influence individual cultural participation.

Christin found that sex is an essential determinant by analyzing the survey data of public art participation in the United States in 2008, and women were more inclined to engage in high-level cultural activities than men [41]. Willekens and Lievens analyzed the data of Flanders' attendance in a survey in 2009 and found that the cultural participation rate of groups with a low-income level, single status, and small social network was low [11]. Campbell et al. found that occupational differences 
can cause differences in individual cultural consumption [42]. Therefore, we proposed the fourth hypothesis as follows.

Hypothesis 4 (H4). The age, sex, and occupation of the public also impact their cultural participation.

\section{Materials}

The research data included survey data of the cultural participation of the audience who have visited the Hubei Provincial Museum (S1, $N=2028)$, and the public cultural participation of Chinese urban residents (S2, $N=2320)$. The Hubei Provincial Museum is located in Wuhan, the capital of the Hubei Province. As a state-level museum established in 1953 and one of eight key museums jointly sponsored by the central and local governments, the Hubei Provincial Museum took the lead in applying the open for free cultural policy in November 2007. More than 240,000 collections are held in the Hubei Provincial Museum, of which about 1000 are grade one cultural relics of the state, so it hosts a large number of visitors every year. The geographical location of Wuhan in China and the location of the Hubei Provincial Museum in Wuhan are shown in Figure 1.

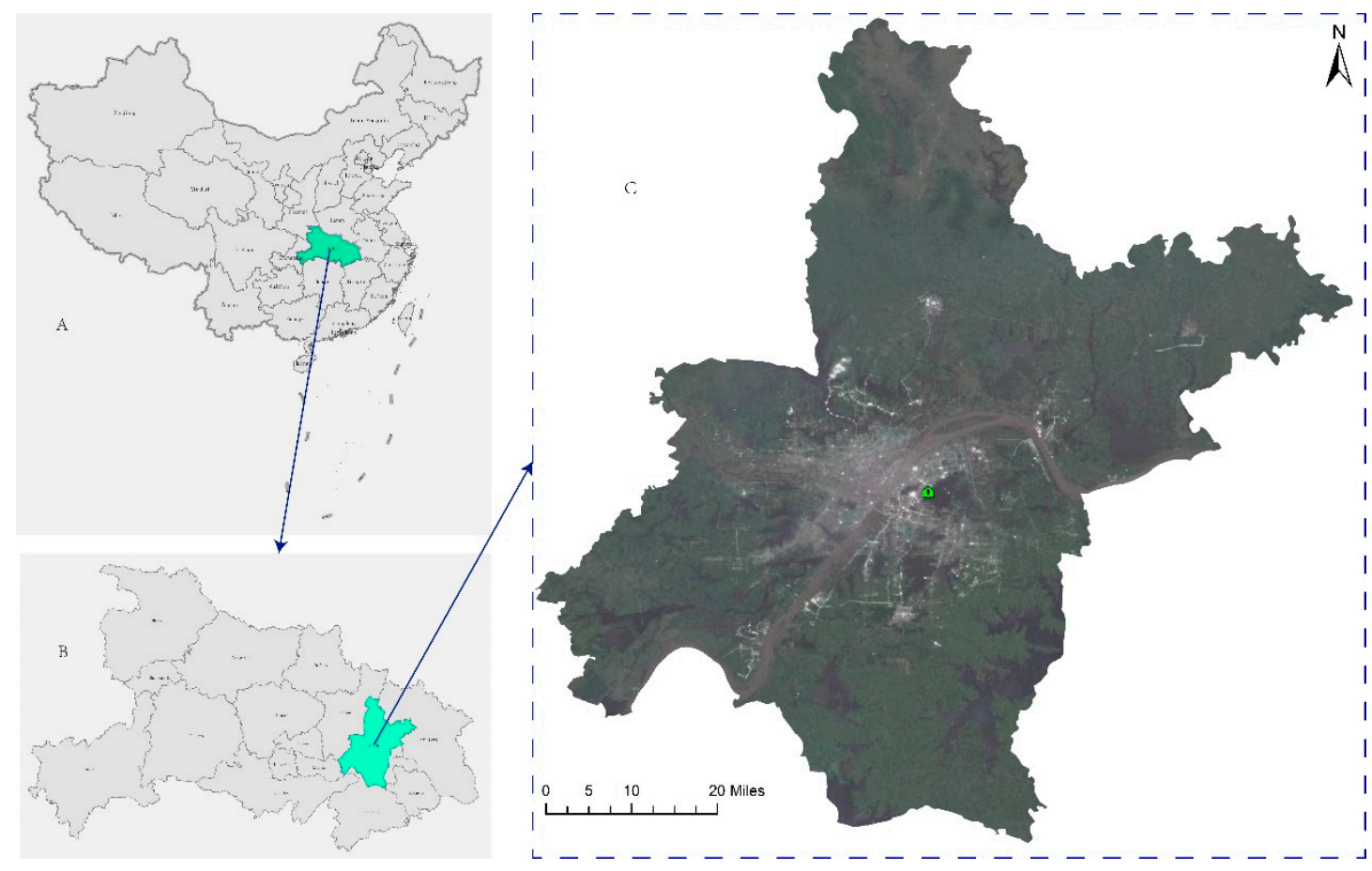

Figure 1. The location of Wuhan city and location of the Hubei Provincial Museum. (A) China, (B) Hubei province, and (C) Wuhan city with a night light image and the location of the Hubei Provincial Museum as the green marker.

\subsection{Basic Characteristics of Surveys Respondents}

According to S1, the sex of the audience of the Hubei Provincial Museum significantly differed, among which the proportion of women is about $17 \%$ higher than men. The age structure shows a single peak distribution, with the highest proportion of 19-25-year-olds, among which the proportion of $19-40$-year-olds was $75 \%$. The percentage of people with a high school education was the highest, at $70.4 \%$. In terms of discipline, people with an educational background in Natural Science and Engineering or Economics and Management Science have the highest proportion of audiences, with values of $32 \%$ and $19.7 \%$, respectively. In terms of economic income, low-income groups accounted for a relatively high proportion, including $41.8 \%$ of the public with a monthly income of less than 1500 yuan, whereas the proportion of high-income groups was low. In terms of occupation, students were 
the main body (55.6\%), followed by company employees $(15.7 \%)$ and teachers or researchers $(10.4 \%)$ (Table 1).

Table 1. Descriptive statistics of survey data of the cultural participation of the audience who have visited the Hubei Provincial Museum (S1, N = 2028), and public cultural participation of Chinese urban residents $(\mathrm{S} 2, \mathrm{~N}=2320)$.

\begin{tabular}{|c|c|c|c|c|}
\hline \multirow{2}{*}{ Item } & \multicolumn{2}{|l|}{$\mathrm{S} 1$} & \multicolumn{2}{|l|}{ S2 } \\
\hline & Category & $\%$ & Category & $\%$ \\
\hline \multirow{2}{*}{ Sex } & Male & 41.42 & Male & 48.75 \\
\hline & Female & 58.58 & Female & 51.25 \\
\hline \multirow{6}{*}{ Age } & $<12$ & 4.64 & $<17$ & 10.91 \\
\hline & $13-18$ & 9.23 & $18-25$ & 27.64 \\
\hline & $19-25$ & 47.80 & $26-35$ & 17.94 \\
\hline & $26-40$ & 27.23 & $36-44$ & 16.43 \\
\hline & $41-60$ & 9.92 & $45-60$ & 18.71 \\
\hline & $>60$ & 1.18 & $>60$ & 8.37 \\
\hline \multirow{7}{*}{ Occupation } & Student (Stu) & 55.60 & Student (Stu) & 28.72 \\
\hline & Civil servants (CS) & 3.06 & Civil servants (CS) & 9.96 \\
\hline & Teacher or researcher (TR) & 10.36 & Teacher or researcher (TR) & 11.04 \\
\hline & Company employee (CEe) & 15.74 & Company employee (CEe) & 18.07 \\
\hline & Company employer (CEr) & 2.27 & Company employer (CEr) & 8.11 \\
\hline & Freelancer (Fre) & 7.30 & Freelancer (Fre) & 8.45 \\
\hline & Others (OcO) & 5.67 & Others $(\mathrm{OcO})$ & 15.65 \\
\hline \multirow{4}{*}{ Education } & $<6$ years & 5.18 & $<6$ years & 7.27 \\
\hline & 12 years & 8.04 & 12 years & 36.49 \\
\hline & 16 years & 70.45 & 16 years & 49.65 \\
\hline & $>16$ years & 16.33 & $>16$ years & 6.58 \\
\hline \multirow{10}{*}{ Discipline } & History (His) & 2.38 & & \\
\hline & Art (Art) & 6.25 & & \\
\hline & Literature (Lit) & 9.35 & & \\
\hline & Education $($ Edu $)$ & 5.37 & & \\
\hline & Economics and Management Science (EMS) & 19.63 & - & - \\
\hline & Law (Law) & 4.26 & & \\
\hline & Natural Science and Engineering (NSE) & 31.97 & & \\
\hline & Agronomy and Medicine (AM) & 7.36 & & \\
\hline & Others (DisO) & 13.16 & & \\
\hline & Interdisciplinary & 0.28 & & \\
\hline \multirow{6}{*}{ Income } & $<1500 \mathrm{RMB}$ & 41.75 & $<1000$ RMB & 25.66 \\
\hline & 1500-3500 RMB & 16.39 & 1001-2000 RMB & 14.63 \\
\hline & 3501-6000 RMB & 18.30 & 2001-3000 RMB & 20.90 \\
\hline & $6001-10,000$ RMB & 13.98 & $3001-5000 \mathrm{RMB}$ & 23.37 \\
\hline & $10,001-20,000 \mathrm{RMB}$ & 6.57 & $5001-10,000 \mathrm{RMB}$ & 11.68 \\
\hline & $>20,000 \mathrm{RMB}$ & 3.01 & $>10,001 \mathrm{RMB}$ & 3.76 \\
\hline
\end{tabular}

\subsection{Spatial Relationship between People and the Museum}

By comparing the time individuals spend at and their distance from the museum in the two sets of survey data, we found that those in S1 had to travel 0.5-2 $\mathrm{h}$ to visit the museum, but only $1 \mathrm{~h}$ for those in S2 (Table 2). This difference was mainly due to the regional scope of cities and the geographical distribution of public cultural facilities. Figure $1 \mathrm{C}$ was generated by superimposing multispectral and night light remote sensing images. Night light remote sensing can roughly reflect locations of human activity. The figure shows that the Hubei Provincial Museum is not located at the center of human activities in the city, especially considering Wuhan is one of the megacities in China. Secondly, the time distance in $\mathrm{S} 2$ is the distance traveled by the individual to the nearest museum, and in S1, the time distance is the distance from the individual's residence to the Hubei Provincial Museum. However, for some respondents, the Hubei Provincial Museum may not be the closest public museum. 
Table 2. Distribution of distance between the individual's residence and the museum described by time.

\begin{tabular}{ccccc}
\hline \multirow{2}{*}{ Item } & \multicolumn{2}{c}{ S1 } & \multicolumn{2}{c}{ S2 } \\
\cline { 2 - 5 } & Category & Percent & Category & Percent \\
\hline \multirow{3}{*}{ Distance } & $<0.5 \mathrm{~h}$ & $16.44 \%$ & $<0.25 \mathrm{~h}$ & $26.23 \%$ \\
& $0.5-1 \mathrm{~h}$ & $42.71 \%$ & $0.25-0.5 \mathrm{~h}$ & $40.42 \%$ \\
& $1-2 \mathrm{~h}$ & $26.44 \%$ & $0.5-1 \mathrm{~h}$ & $23.34 \%$ \\
& $2-3 \mathrm{~h}$ & $6.80 \%$ & $>1 \mathrm{~h}$ & $10.01 \%$ \\
\hline
\end{tabular}

\subsection{People's Cultural Participation Pattern}

The survey based on Chinese urban residents showed that more than half of the public visited the museum in the past year. According to the results of the museum attendance survey, the public mainly visits museums as a hobby $(66.19 \%)$, tourism $(37.05 \%)$, accompanying relatives and friends $(19.04 \%)$, and education of children (17.02\%). The public mainly chooses to visit museums during holidays $(60.76 \%)$ and weekends $(51.01 \%)$, whereas the visits during working days $(19.85 \%)$ are much lower. The public usually visits the museum only once a year $(75.04 \%)$, and the proportion of multiple visits is small. Usually, people tend to visit the museum for $1-2 \mathrm{~h}(80.50 \%)$ (Table 3 ).

Table 3. Distribution of cultural participation of the museum.

\begin{tabular}{ccc}
\hline Item & Category & Percent \\
\hline \multirow{2}{*}{ Museum Attendance } & Yes & 54.53 \\
& No & 45.47 \\
Frequency & 1 time & 75.04 \\
& 2 times & 12.35 \\
& 3 times & 4.52 \\
& $>4$ times & 8.09 \\
Duration & $<1 \mathrm{~h}$ & 2.66 \\
& $1-2 \mathrm{~h}$ & 39.76 \\
& $2-3 \mathrm{~h}$ & 40.74 \\
& $3-4 \mathrm{~h}$ & 11.57 \\
& $>4 \mathrm{~h}$ & 5.27 \\
Motivation & Professional needs (PN) & 8.37 \\
& Education of children (EC) & 17.02 \\
& Tccompanying relatives and friends (ARF) & 19.04 \\
& Tourism (Tour) & 37.05 \\
Timing & Hobby (Hob) & 66.19 \\
& Others (WhyO) & 2.94 \\
& Weekday & 19.85 \\
& Weekend & 51.01 \\
& Holiday & 60.76 \\
\hline
\end{tabular}

\section{Methods}

To explore how the Chinese public's cultural participation behavior in museums is affected by individual attributes and distance to the museum, we preprocessed the museum survey data, then extracted key features of the motivation and timing of museum participation, and then explored the influence mechanism of individual attributes and the distance from the museum on the cultural participation behavior of the museum. We finally drew conclusions based on the analysis results (Figure 2). 


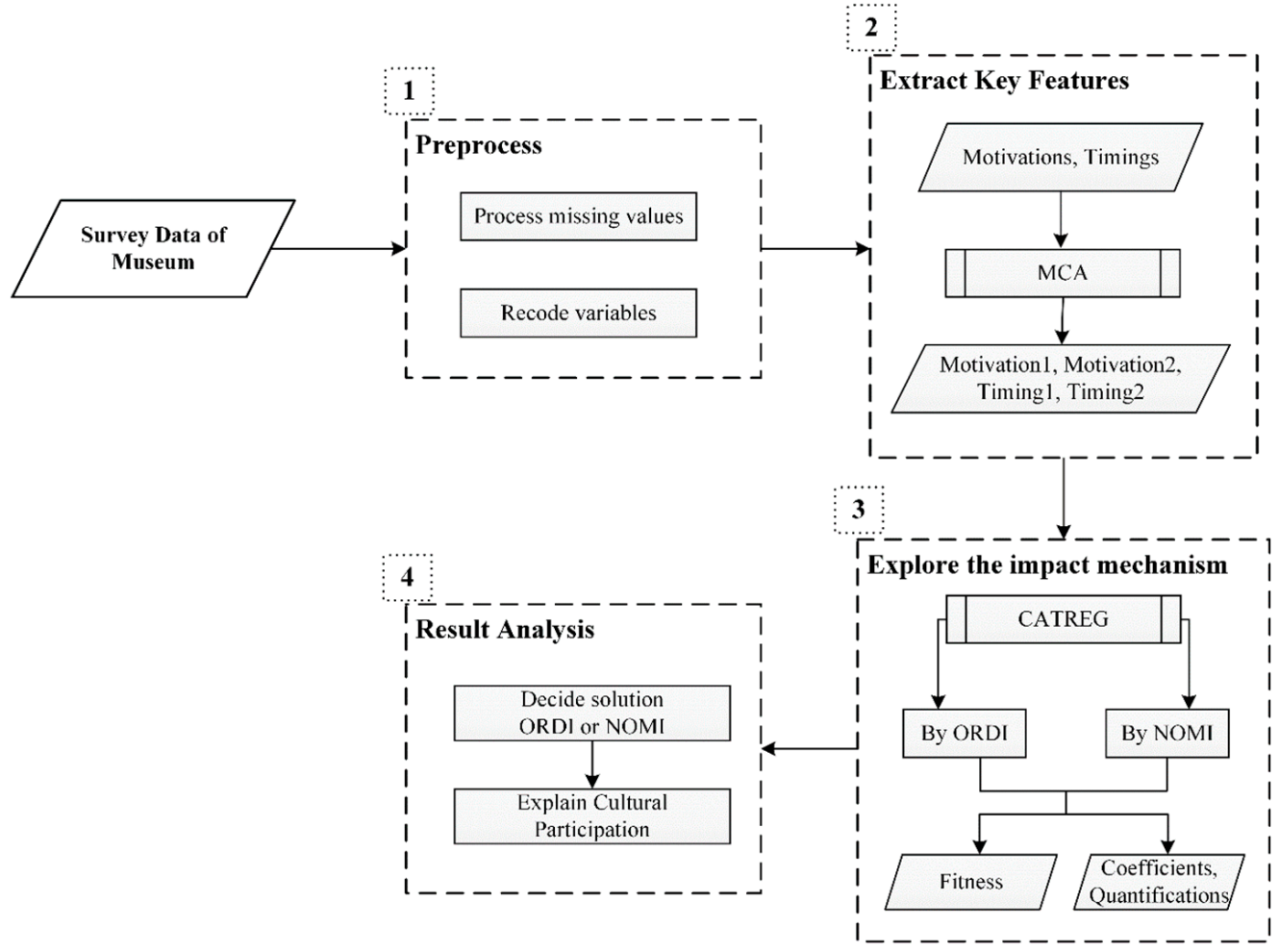

Figure 2. Flowchart of analysis of cultural participation of the Chinese public in museums.

We focused on the five dimensions of museum cultural participation, including whether the public visits the museum and the motivation, frequency, duration, and timing of the museum visits. Firstly, the original data were preprocessed from the perspective of missing values and encoding. The public's motivation and timing for visiting the museum were multiple response variables. To identify the key features, a dimension reduction operation was applied for motivation and the timing of museum visits to retain the first two key features using MCA, and the relationships of the key features were extracted for frequency and duration. Then, CATREG was applied to explore the mechanism through which the public's museum cultural participation is affected. Finally, by comparing the ordinal (ORDI) and nominal (NOMI) results, more accurate models were chosen and the influence of individual attributes and distance to the museum on the individual's participation in museum culture was identified.

\subsection{Preprocessing Museum Survey Data}

The survey data involved in this study were respectively collected by recruiting college student volunteers. S1 was collected using a questionnaire survey with museum visitors at the Hubei Provincial Museum in January-February 2018, and 2028 participants completed the survey. S2 was collected using a questionnaire survey with residents in 41 cities of 17 provinces in China January-February 2016, and 2320 participants completed the survey. For the case where the respondent is a child, we obtain the child's consent through their parents, and our investigator or the child's parent will assist the child during the investigation. The questions of S1 and S2 were compiled differently. The questions for the independent variables of S1 and S2 were similar, including what is your sex, how old are you, what is your occupation, what is your education level, what is your discipline (only for S1), what is your monthly income (in RMB), and how far is your home from the museum. Meanwhile, the questions for dependent variables were completely different. S1 was concerned about the frequency, duration, motivations, and timings of museum visiting, and its questions included how often do you visit a museum, how long do you usually stay in the museum once, what do you visit the museum for, 
and how do you generally timing your museum visit. S2 was concerned about whether the public is willing to visit the museum, by asking if they visited museums last year.

To ensure that the feature extraction of cultural participation behavior and exploration of the impact mechanism of cultural participation behavior were performed correctly, the original data were pre-processed, mainly from the aspects of missing values and category encoding, including dropping records with serious missing values, ensuring categories encoding the categorical variable were positive integers, etc. Some categories with a very small proportion of the variable were merged, such as merging the occupation of farmer with other types.

\subsection{Extracting Key Features of the Public's Motivation and Timing for Museum Visits with MCA}

To determine the motivation of the museum audiences, the survey asked, "What do you visit museum for?" In China, as a necessary public cultural space, museums provide the public with functions such as cultural education, leisure and entertainment, and social networking. They are also important points of interest (POIs) for attracting tourists. Therefore, the motivation for attending the museum included professional needs (PN), education of children (EC), accompanying relatives and friends (ARF), tour (TOUR), hobbies (HOB), and more. The surveyed museum audience could choose the corresponding motivation according to their actual situation. Table 3 shows that the museum audience in China mainly visits museums as a personal hobby, followed by tourism. Many people who reported viewing the museum as a social place or for educating their children through the services offered by the museum. In terms of the timing of museum visits, people are more likely to visit the museum on holidays or weekends.

The key features of the motivation and timing of museum visits were extracted using MCA. Since the motivation and timing of the public's museum visits were multiple response variables, to focus on the key features of the cultural participation behavior of Chinese people in the museum, we extracted and retained the first two features of the motivation and timing of the museum visit for further analysis. Dimensionality reduction is an essential method used during data feature extraction. A particular information enrichment algorithm is used to extract fewer variables than the original variables, while preserving the original variable information as much as possible. Principal component analysis (PCA) and MCA are the mainstream methods of dimensionality reduction, where MCA is a widespread application of categorical data of PCA, which is suitable for numerical data [43]. Since the motivation and timing of museum visiting were categorical data, we used MCA for analysis during feature extraction. The MCA process allows the use of supplementary variables that do not participate in the actual dimensionality reduction calculation process, but can be projected into MCA's result space. Using the frequency and duration of participation as supplementary variables in the MCA of participation motivation, we explored whether the key features of motivation for museum visits affected the frequency and duration of the museum visit. The key features were extracted and processed as shown in Figure 3.

Firstly, a dummy variable set was created for MCA. Because questions regarding the public's motivation and timing for visiting the museum were multiple response answers, and MCA is a feature extraction process for multiple variables, it was essential to create a dummy variable set based on motivation and schedule, respectively. For example, the dummy variable set for motivation was composed of all categories of the original motivation variable. "Hobby" was a dummy variable in the dummy variable set of motivation, where a value of 1 represents individual visits to the museum for a hobby and 2 represents that the individual did not visit the museum as a hobby.

Then, MCA was performed. The purpose of using MCA was to extract the key features of motivation and timing of museum cultural participation for CATREG analysis, and explore the relationship of the key features extracted to frequency and duration. When performing the analysis, variables of motivation or timing were set as the analysis variables, and the variables of both frequency and duration were set as supplementary variables. Only the first two features extracted, motivation and timing, were considered in further analysis, so there were two dimensions of the solution. To give 
certain realistic meaning to the key features of motivation and timing, and to analyze their relationship with frequency and duration, the categories of all variables were quantified; that is, the category quantifications were retained. To explore the cultural participation model of motivation and timing, the object scores were retained in MCA.

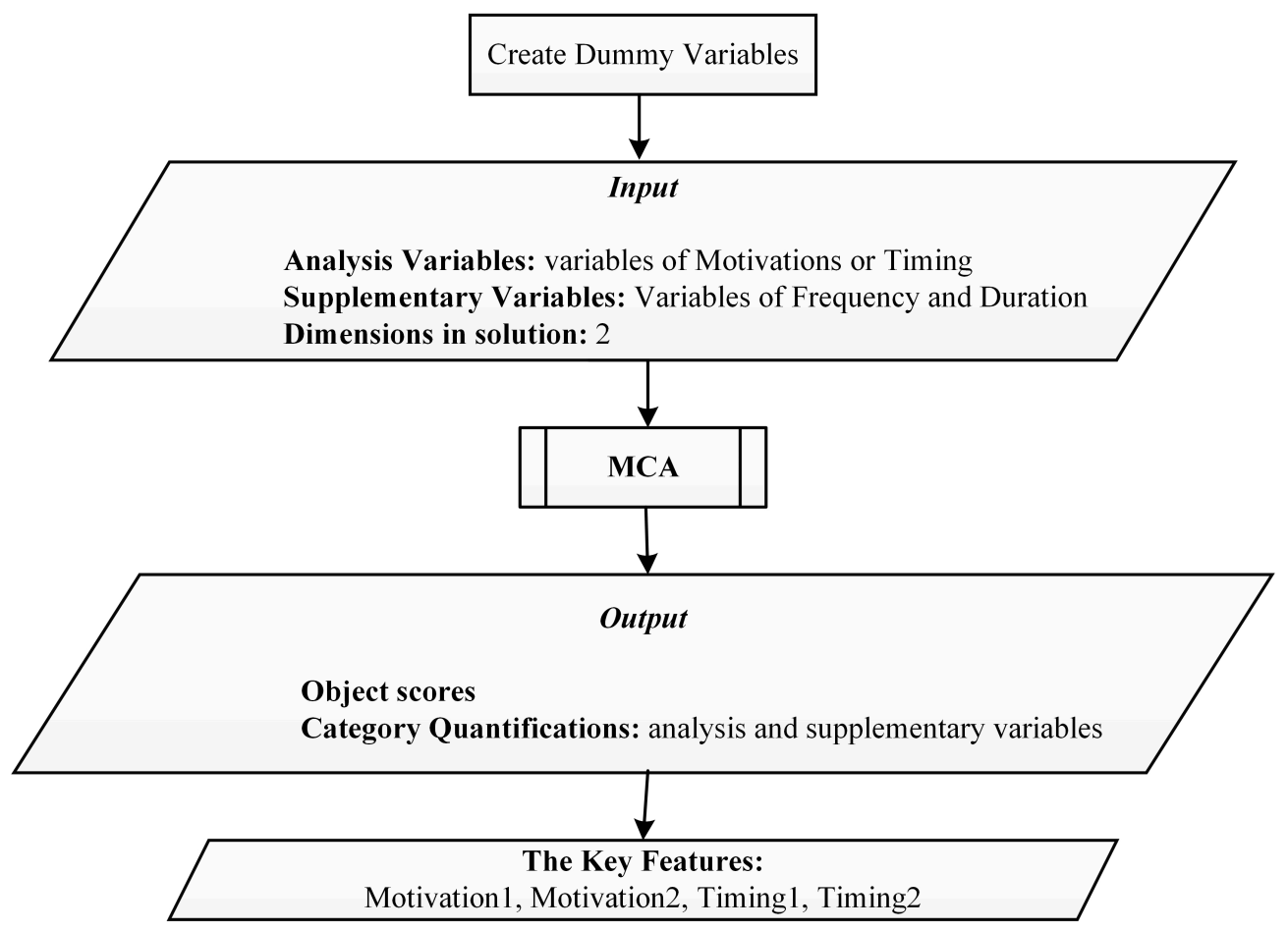

Figure 3. Extracting key features of motivations and timings of cultural participation in the museum.

\subsection{The Impact Mechanism of Cultural Participation Behavior of Chinese Public in the Museum by CATREG}

CATREG was used to analyze the cultural participation regression model, which contained categorical variables. Existing research methods have transitioned from simple descriptive statistics to regression. To analyze cultural participation behavioral preferences, DiMaggio and Mukhtar [44], Glorieux et al. [45], and Kraaykamp et al. [7] used frequency distributions and contingency tables. To explore the impact model of multiple factors on cultural participation, various researchers [45-48] used multiple regression, Upright [49] and Brook [50] used multiple category logistic regression, and Christin [41] used negative binomial regression. Regression analysis is becoming increasingly popular in the study of cultural participation models. Cultural participation research is usually based on survey data that mainly consists of categorical variables. Negative binomial regression is often applied in analyses where the dependent is a numeric variable. In multiple regression analysis, codes representing the classification of variables are treated as numeric values that deviate from the meaning represented by the actual survey data. Although logistic regression analysis can deal with the regression of categorical variables, the significance of the independent variables in the analysis results is the significance of the differences between the classifications and baseline values, which may lead to incomplete interpretations in specific situations. The difficulty of interpreting the analysis results increases with the number of categories of variables. We introduced the CATREG method, which combines regression and optimal scaling for data analysis and quantifies variable categories, by assigning numerical values to the categories to ensure that the regression model has better interpretation and prediction capabilities [51].

The regression analysis has become the mainstream method for studying the influence mechanism of cultural participation. It includes many methods, and each method has a specific applicable data distribution and nature, some of which can only be used if the data meet certain assumptions. As the 
data used in this study were categorical and given the lack of empirical linear relationships between the dependent and independent variables, we used CATREG to explore the impact mechanism of cultural participation behavior in the museum for the Chinese public. The nature of simple linear regression is minimization, as shown in the following expression:

$$
\|X b-z\|^{2}
$$

where $X$ is a matrix with independent variables as columns and cases as rows, $b$ is the weight vector of independent variables, and $z$ is the vector of the dependent variable. CATREG which can provide an optimal assignment of quantitative values to qualitative scales and realize linear regression [52], is closely related to the alternating conditional expectation (ACE) [53], and is suitable for categorical data regression [51]. The basic idea of multiple regression and optimal scoring using alternating least squares is as follows:

$$
\left\|X^{*} b-z^{*}\right\|^{2}, \text { where } X_{j}^{*}=\phi\left(X_{j}\right), j=1, \ldots, \operatorname{mand} z^{*}=\theta(z)
$$

where both $\phi$ and $\theta$ are nonlinear functions, and $m$ is the number of independent variables. For CATREG, $\phi$ and $\theta$ are functions of $G$ and $y$, where $y$ denotes the category quantifications for the independent or dependent variable. $G_{j}$, which is defined by a categorical variable $x_{j}$, is a binary matrix with $n$ rows and $l_{j}$ columns, and $g_{i r(j)}$ is defined as

$$
g_{i r(j)}=\left\{\begin{array}{l}
1, x_{i j}=r \\
0, x_{i j} \neq r
\end{array}, \text { where }=1, \ldots, l_{j} .\right.
$$

Based on that, the objective function of CATREG is

$$
\left\|\sum_{j}^{m} b_{j} G_{j} y_{j}-G_{r} y_{r}\right\|^{2}
$$

Objective function optimization is realized by iteration as follows: (1) initialize category quantifications of all categorical variables with a random or numerical method and regression coefficients. The initialization by random treats variables as numerical, whereas the numerical initialization executes the iteration scheme twice. The first cycle is run by random and the second cycle starts with the specified scaling levels and the results of the first cycle. (2) Update category quantifications of dependent variables, (3) update category quantifications of independent variables and regression weights, and (4) conduct a convergence test and repeat steps (2) and (3) if needed. The use of CATREG for categorical data analysis is gaining increasing acceptance, including in psychology $[54,55]$ and management [56]. Therefore, we chose to apply CATREG for exploring the impact mechanism of Chinese cultural participation in a museum.

To test whether the variables with actual ordered meaning monotonously affected the cultural participation of museums, CATREG was performed with the optimal scaling level of ordinal independent variables set by ordinal and nominal. When CATREG quantifies categorical variables, multiple options are available for the optimal scaling level of independent and dependent variables, including ordinal, nominal, numeric, and so on. Our research purpose was to explore the influence mechanism of different independent variables on cultural participation in museums, which included whether it has a significant impact and how it affects participation (positive or negative, monotonic, U-shaped, etc.) Besides, both variables in our research data were categorical, so only ordinal and nominal were considered when setting the optimal scaling level. If the optimal scaling level is set to ordinal, the optimal scaled variable will retain the order information of the observed variable; when it is set to nominal, the order information of the observed variable is ignored. When using CATREG to analyze cultural participation data, the dependent variable was set to ordinal or nominal according to its nature, the nominal categorical independent variables were set to nominal, and the setting of the optimal scaling level for the ordinal categorical independent variables contained two solutions: 
ordinal (Sol1) and nominal (Sol2). As such, we were able to conclude whether the ordinal categorical independent variables have a monotonic effect on the dependent variable and the influence mechanism of different independent variables on the cultural participation behavior of a museum visit. It is processed as shown in Figure 4.

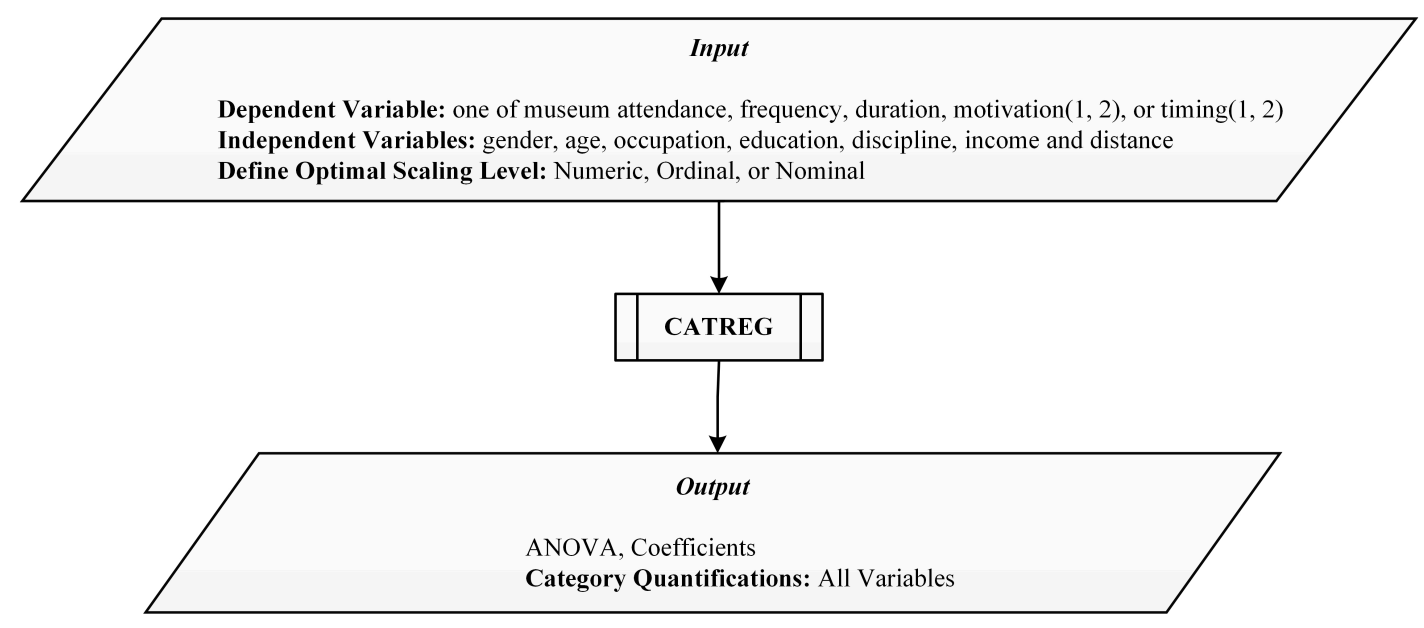

Figure 4. Exploring the impact mechanism of cultural participation behavior in the museum for the Chinese public.

Firstly, we set the independent and dependent variables. CATREG has a similar formula to general regression, including multiple independent variables and one dependent variable. The independent variables of the different models in this study were consistent, including sex, age, occupation, education, discipline (except "whether attend"), income, and distance, but the dependent variable depends on the target behavior of the model and is one of the behavior variables, including whether attend, frequency, duration, the first two key features of motivations (motivation1, motivation2), and timings (timing1, timing2). Secondly, the optimal scaling level of variables in CATREG was defined. Optimal scaling, which is a sub-process of CATREG, is employed to assign numerical quantifications to the categories of each variable. The difference in the optimal scale level leads to different optimally scaled variables. For numeric (NUME), the value of the observed variable is directly preserved as the optimally scaled variable. For ordinal (ORDI), the optimal scaled variable preserves the order of categories of the original variable. For nominal (NOMI), the optimal scaled variable only preserves the grouping information in categories. The observed dependent variables were both ordinal and numerical types, and they make sense of the research goals. For example, the frequency of participation indicates the intensity of individual cultural participation in the museum. Therefore, their optimal scaling level was defined as their nature. The observed independent variables were categorical variables, including ordinal (age, education, income, and distance) and nominal (sex, occupation, and discipline). The optimal scaling level of nominal was directly set to NOMI, and that of ordinal variables was set according to the two solutions of ORDI and NOMI, to explore whether the ordinal variables monotonously affect the cultural participation behavior of public museums according to their ordinal nature. Finally, the output of CATREG was set. The output needs to include the coefficient of determination $\left(R^{2}\right)$ and ANOVA, which are used to judge which of the ORDI and NOMI solutions is more explanatory. Simultaneously, the coefficients and category quantifications need to be retained to explain which independent variables significantly affect individual museum cultural participation and their effect pattern.

\subsection{Result Analysis}

The CATREG results include $R^{2}$, ANOVA, coefficients, and category qualifications. Firstly, according to ANOVA and $R^{2}$, we determined which of ORDI or NOMI is better for interpreting the cultural participation model. The significance (Sig.) of regression in ANOVA shows whether the model 
is effective, and by comparing the $R^{2}$ of the ORDI and NOMI solutions for the same model, the larger was chosen as the interpretation solution. Then, the influence of variables on cultural participation behavior was explained according to the selected solution of each model. The Sig. of the independent variable in coefficients determines whether it has a significant effect on the dependent variable and the $\beta$ is an estimate of its contribution. Category quantifications describe the difference in the effect of each category of the independent variable on the dependent variable.

\section{Results}

\subsection{Key Features of Motivation and Timing of Museum Visits}

Cultural and functional are the first two key features motivating museum visits for the Chinese public. Motivation describes the desire to achieve the target behavior, and people may show different features in terms of the source and intensity of motivation in the same behavior. For a museum visit, the behavior of cultural participation varies in terms of the goal of the public. The theories of motivation explain the formation, classification, and function of motivation, including the hierarchy of needs theory [37], the two-factor theory [57], and intrinsic and extrinsic motivation [58]. The MCA results of motivation for museum visits are shown in Figure 5. According to the joint plot of timing categories, the most prominent difference comes from the quantification trend of $\mathrm{HOB}$ and EC or ARF, and PN and TOUR are in the middle on the first key dimension (Dim1). Given the nature of these behavioral motivations, Hob had the most influential cultural demand features, and PN and Tour also reflected the motivation with specific cultural or leisure traits, whereas EC and ARF expressed an individual need that is educational or social rather than cultural. Meeting the cultural needs of the public is the fundamental purpose of a museum as a public cultural service facility. Individual cultural needs represent the intrinsic motivation of the public to visit the museum and are stronger than other motivations. Therefore, Dim1 was defined as cultural motivation. In the second key dimension (Dim2), the quantitative values of EC and ARF were the largest, the quantitative values of PN and Hob were relatively low, and the quantitative value of Tour was the lowest. From the perspective of the city's public cultural space, the museum provides public spaces for children's education and social interactions. Public spaces also cater to professional needs or personal hobbies through abundant collections and exhibitions. Since museums are one of the types of cultural attractions in the city, visiting museums can be considered a tourist activity, especially for foreign tourists. By comparing information, such as the Wuhan attractions records and the number of reviews and scores of attractions from Ctrip.com, which is a sizeable Chinese tourist information website, Hubei Provincial Museum was not the most attractive attraction. The function of the museum as a public space seems to be a reasonable explanation for Dim2. Therefore, Dim2 was defined as functional motivation and was biased toward external motivation.

Although motivations such as the education of children and accompanying relatives and friends are not as evident in the two dimensions as hobbies and tourism, it shows that Chinese museums as a public cultural space meet the public needs for public cultural education and social interaction. Through the projection of the frequency and duration in the MCA, we found that the intensity of an individual's cultural needs positively extends the duration of museum visits; functional participation motivation reduces the individual museum visit frequency.

Facilitation and efficiency are the first two key features of timing for cultural participation in the museum. The questionnaire survey provided weekday, weekend, and holiday as the options for the timing of museum visits. We classified the timing this way because this time division is most conducive for mapping their behavioral decisions to specific options without confusion, and these time divisions contain information, such as the length of leisure time and the strength of social needs. The MCA results of museum visit timing are shown in Figure 6. For Dim1, the museum visit timing tends to rely on the availability of free time. Timing is the process of determining the time factor in the behavior of museum visits and time is a resource-related facilitating condition [59] for perceived behavioral control 
which is viewed as one of the determinants of individual behavior [60]. Holidays provide the most time convenience, whereas weekdays are the least convenient. This is consistent with the perceived facilitation of perceived behavioral control [61], meaning that free time provides the opportunity for individual cultural participation in behavior; simultaneously, the lack of free time can also hinder individual cultural participation in behavior. Therefore, Dim1 was defined as facilitation-based timing. For Dim2, weekdays had the smallest quantification, which still seems to be related to free time, but the weekends had a larger quantification than holidays. Usually, the duration of museum visits generally does not exceed half a day, and the weekends provide less free time than a holiday, which means that visiting a museum on the weekend seems to be more efficient in terms of time than visiting during a holiday. To increase time efficiency, short-term behaviors such as museum visits should be conducted on the weekend and time-consuming activities should be arranged during a holiday. This is consistent with the outcome evaluation of the behavior attitude framework, taking time efficiency as the key factor for the outcome evaluation to decide when to visit a museum. Therefore, Dim2 was defined as efficiency-based timing.

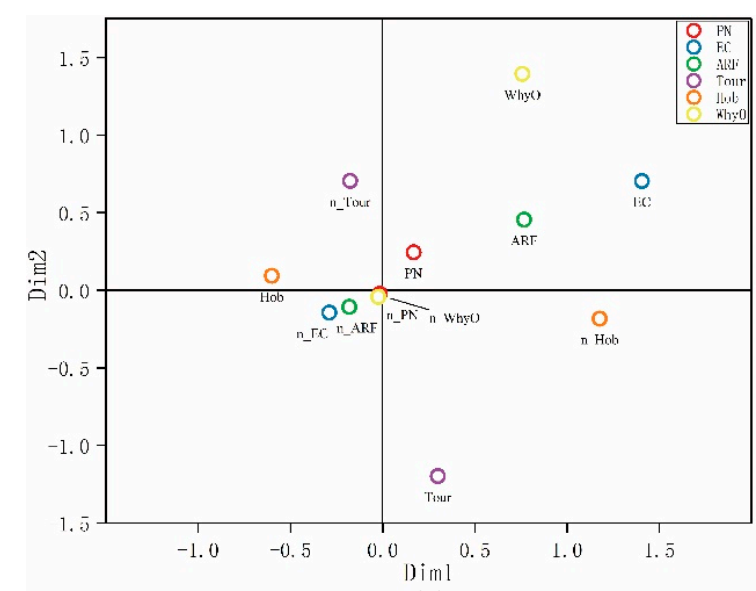

(a)

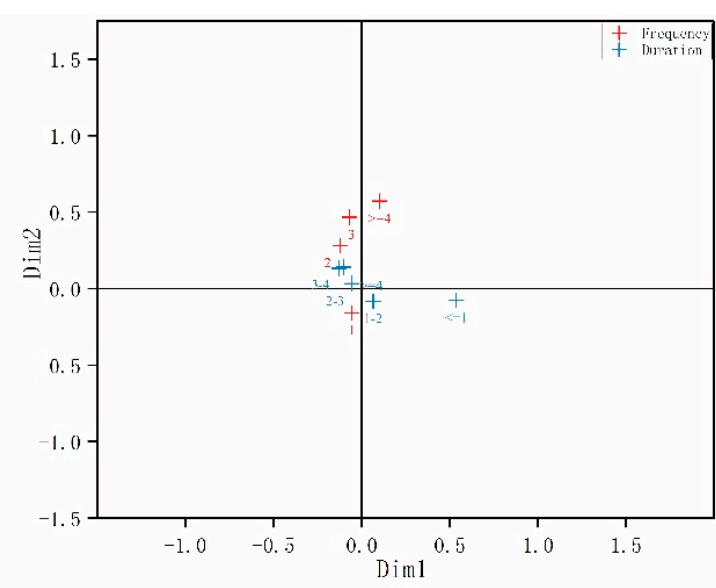

(b)

Figure 5. Multiple correspondence analysis (MCA) based on the motivation of cultural participation in (a) a joint plot of motivation categories and (b) the projection of frequency and duration in MCA.

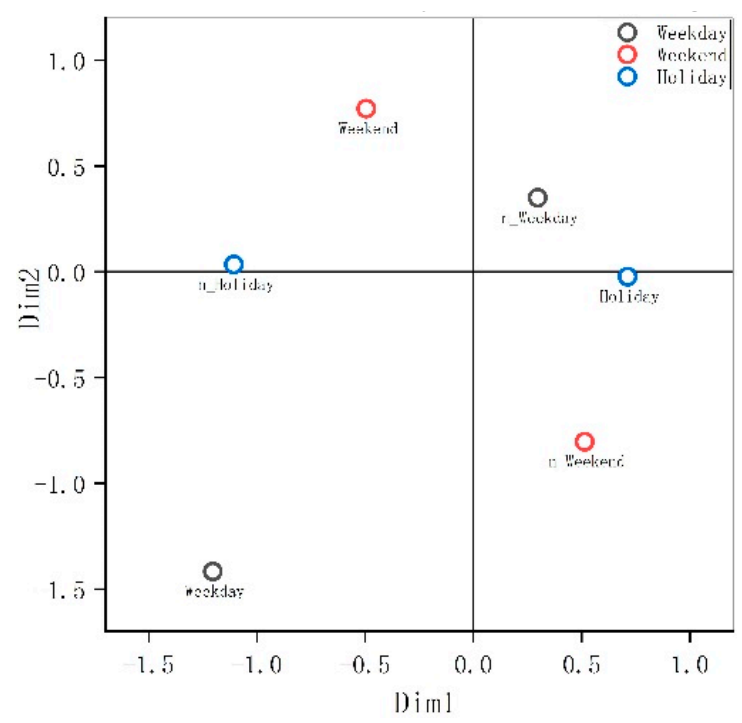

Figure 6. MCA based on the timing of cultural participation for discrimination measures. 


\subsection{Effects on the Chinese Public's Museum Visits}

\subsubsection{The Non-Monotonic Nature of the Ordinal Variables Affects Museum Cultural Participation}

The variables with actually ordered meaning non-monotonically affected the cultural participation of museums. The $R^{2}$ of the CATREG results describes the degree of model interpretation. Comparing the ORDI and NOMI analysis solutions, the $R^{2}$ of all models in NOMI was more significant than in ORDI, which suggested that models based on NOMI were more predictive than those based on ORDI. We concluded that age, education, income, and distance non-monotonically affect the cultural participation of museums. Some variables were significant in models based on NOMI compared with ORDI, indicating that models based on the monotonicity hypothesis may underestimate the impact of some variables on cultural museum participation (Table 4).

According to the result of NOMI, education has a significant impact on museum attendance, the cultural motivation and the facilitation timing of visiting the museum, and discipline was significant in all models, which indicates that $\mathrm{H} 1$ is supported; income was significant in all models, as was distance, rather than only affecting whether people visit the museum and museum visit frequency, which indicates that $\mathrm{H} 2$ and $\mathrm{H} 3$ are supported; occupation was also significant in all models; sex and age also had a broader influence on cultural participation in museums, which indicates that $\mathrm{H} 4$ is supported.

Table 4. Categorical regression (CATREG) results for cultural participation in museums.

\begin{tabular}{|c|c|c|c|c|c|c|c|}
\hline Variable & $\begin{array}{l}\text { Museum } \\
\text { Attendance }\end{array}$ & Frequency & Duration & $\begin{array}{l}\text { Cultural } \\
\text { Motivation }\end{array}$ & $\begin{array}{l}\text { Functional } \\
\text { Motivation }\end{array}$ & $\begin{array}{l}\text { Facilitation } \\
\text { Timing }\end{array}$ & $\begin{array}{c}\text { Efficiency } \\
\text { Timing }\end{array}$ \\
\hline \multicolumn{8}{|c|}{ Sol1: ORDI } \\
\hline Sex & 0.007 & 0.054 & $0.103 *$ & 0.063 & 0.012 & 0.063 & 0.069 * \\
\hline Age & $0.097^{* * *}$ & 0.098 & 0.125 & $0.156^{*}$ & 0.120 & $-0.123^{* *}$ & 0.078 \\
\hline Occupation & $0.176^{* * *}$ & $0.191^{* * *}$ & $0.125^{* * *}$ & $0.069^{* *}$ & $0.071 *$ & $0.126^{* * *}$ & $0.170 * * *$ \\
\hline Education & $0.188^{* * *}$ & -0.091 & -0.071 & $-0.185^{* * *}$ & -0.062 & $-0.142^{* * *}$ & -0.009 \\
\hline Discipline & & $0.200^{* * *}$ & $0.152 * * *$ & $0.079 * * *$ & $0.110^{* * *}$ & $0.110^{* * *}$ & $0.077 * * *$ \\
\hline Income & -0.023 & -0.094 & 0.091 & 0.029 & 0.057 & 0.023 & -0.097 \\
\hline Distance & $0.069^{* * *}$ & $-0.107^{* *}$ & 0.088 & 0.039 & 0.081 & -0.067 & 0.033 \\
\hline$R^{2}$ & 0.081 & 0.122 & 0.068 & 0.085 & 0.067 & 0.067 & 0.042 \\
\hline$F$ & $12.489^{* * *}$ & $5.075^{* * *}$ & $2.871^{* * *}$ & $3.818^{* * *}$ & $3.397^{* * *}$ & $2.939 * * *$ & $1.821 * *$ \\
\hline \multicolumn{8}{|c|}{ Sol2: NOMI } \\
\hline Sex & 0.005 & 0.048 & $0.098 *$ & 0.070 * & 0.003 & $0.068 *$ & $0.073 *$ \\
\hline Age & $0.129^{* * *}$ & 0.080 & 0.133 & $0.187^{* * *}$ & $0.183^{* * *}$ & $0.134^{* * *}$ & $0.108^{* * *}$ \\
\hline Occupation & $0.145^{* * *}$ & $0.169^{* * *}$ & $0.123^{* * *}$ & $0.107^{* * *}$ & $0.097^{* * *}$ & $0.123^{* * *}$ & $0.192 * * *$ \\
\hline Education & $0.219^{* * *}$ & 0.100 & 0.094 & $0.155^{* * *}$ & 0.060 & $0.134^{* * *}$ & 0.055 \\
\hline Discipline & & $0.197^{* * *}$ & $0.156^{* * *}$ & $0.083^{* * *}$ & $0.113^{* * *}$ & $0.110^{* * *}$ & $0.076^{* * *}$ \\
\hline Income & $0.052^{* * *}$ & $0.093^{* * *}$ & $0.094^{* *}$ & $0.084^{* *}$ & $0.063^{* *}$ & $0.053 *$ & $0.086^{* *}$ \\
\hline Distance & $0.074^{* * *}$ & $0.132 * * *$ & $0.101^{* * *}$ & 0.050 ** & $0.104^{* * *}$ & $0.082^{* * *}$ & $0.061^{* * *}$ \\
\hline$R^{2}$ & 0.088 & 0.131 & 0.075 & 0.091 & 0.085 & 0.072 & 0.053 \\
\hline$F$ & $9.513^{* * *}$ & $4.468^{* * *}$ & $2.411^{* * *}$ & $2.958^{* * *}$ & $2.760 * * *$ & $2.292^{* * *}$ & 1.656 * \\
\hline
\end{tabular}

Note: ${ }^{*}$ means $0.01<$ Sig. $<=0.05,{ }^{* *}$ means $0.001<$ Sig. $<0.01$, and ${ }^{* * *}$ means Sig. $<0.001$.

\subsubsection{The pattern of Effects on Cultural Participation in Museums}

We explored what and how cultural participation in museums is affected, rather than testing if a monotonic impact exists on museum participation for different factors. As each model in the NOMI scheme had a better model interpretation than the ORDI scheme, models based on NOMI were used to explain the pattern of cultural participation in public museums.

We found that whether an individual visit a museum was significantly affected by age, occupation, education, income, and distance (Figure 7). In general, the influence of age on whether an individual visits a museum was U-shaped, in which people aged 26-35 years were least likely to visit the museum. 
Occupation was also identified as an important factor influencing whether the public visits a museum, and students, teachers, or researchers are more likely to attend museums than others. Education also affected whether the public visits the museum, and people who were more educated were more likely to visit the museum than those who were less educated. Income non-monotonically affected whether the public visits the museum, and individuals with a monthly income of 2000-3000 RMB or higher than $5000 \mathrm{RMB}$ are more likely to visit the museum. Time distance was also found to more strongly impact whether the public visits the museum, and groups farther away from the museum showed a higher willingness to visit.
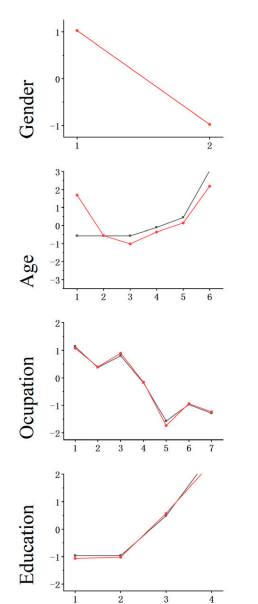

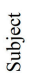
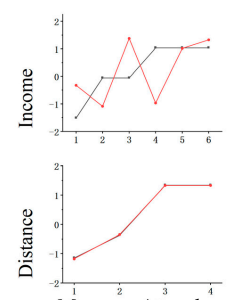

Museum Attendance
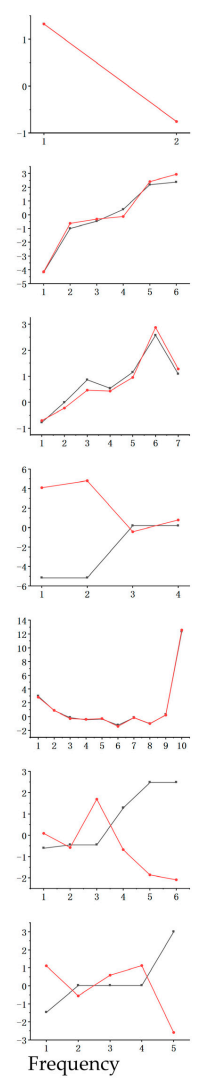
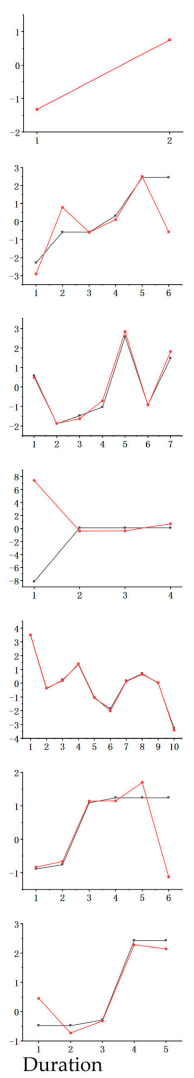
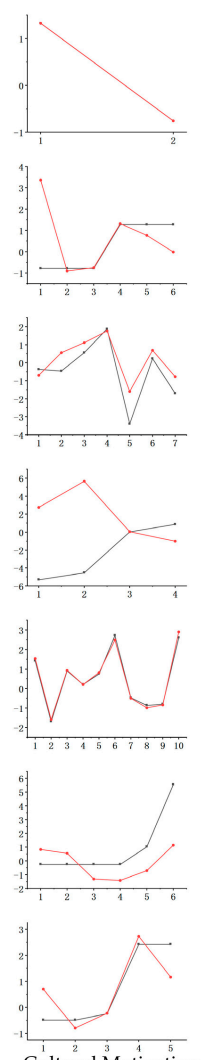

Cultural Motivation
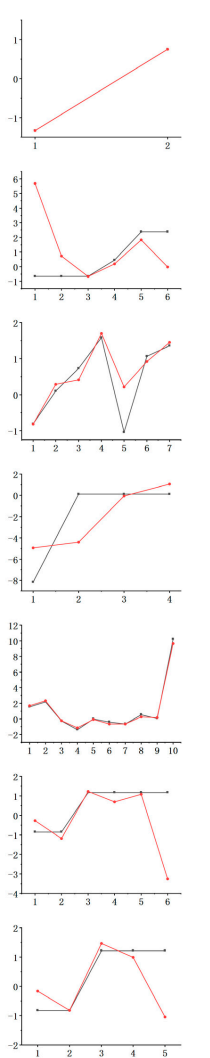

Functional Motivation Facilitation Timing
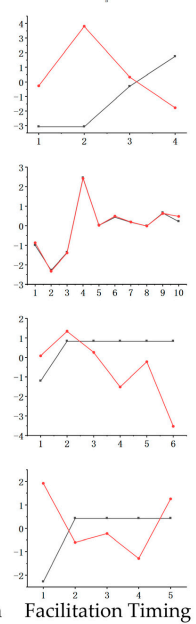
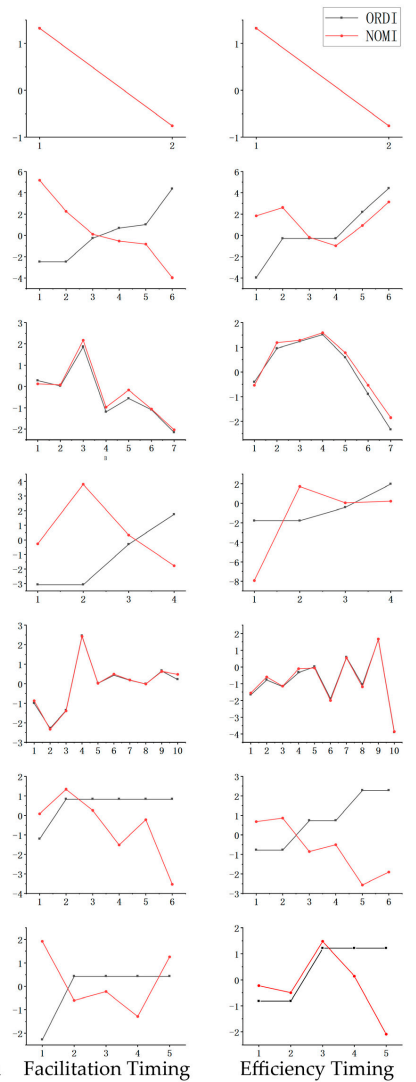

Figure 7. CATREG qualification of variables. The label on the left of the figure represents the X-axis of the subgraph on the same row, and the label at the bottom represents the Y-axis of the subgraph on the same column.

The frequency of museum visits was significantly affected by occupation, discipline, income, and distance. Freelancers visit museums more frequently than others. From the perspective of academic disciplines, people with an interdisciplinary education background were significantly more likely to visit museums more frequently than others, and people with educations in history, art, or literature attended more frequently. Therefore, disciplinary differentiation under the current education system negatively impacts the formation of personal cultural capital. The influence of income on the frequency of museum visits was non-monotonic. Individuals with a monthly income of 3500-6000 RMB had the highest frequency of museum visits, and as income increases to $6000 \mathrm{RMB}$ or more, their frequency museums visit gradually decreases, whereas people whose income is less than 1500 RMB are more likely to visit a museum than those who earn 1500-3500 RMB. Distance has a roughly negative effect on the frequency of museum visits, but the effect is not non-monotonic.

The duration of the museum visit was significantly affected by sex, occupation, discipline, income, and distance. The results suggest that the duration of the museum visit for women is longer than that for men. We also observed a vast difference between people of various occupations, among which 
employers and students were more likely to visit longer. People with an educational background in history were more likely to visit for longer than others. The influence of income on the duration of the museum visit was an inverted U-shape. Distance also had a significant impact on the length of the museum audience's visits. Individuals who lived $0.5-1 \mathrm{~h}$ away from the museum visited for the least amount of time, and individuals who lived further than $1 \mathrm{~h}$ away were more likely to increase visit duration as the distance increased.

Cultural motivation was significantly affected by sex, age, occupation, education, discipline, income, and distance. From the perspective of sex, although women's quantitative values were lower than those for men, the cultural motivation was a negative coordinate. Therefore, women were more motivated to visit museums for cultural needs than men. Individuals under the age of 12 years had the least motivation to visit the museum for cultural needs, whereas those aged 13-25 years reported the highest motivation. Employers and students were more motivated to visit the museum for their own cultural needs than others. From the perspective of educational background, those who were more educated or educated in art had a higher cultural need to visiting the museum, whereas people with secondary education had the lowest cultural need to visiting the museum. Those with a monthly income of 3000-10,000 RMB or who live 0.5-2 h away from the museum also had a stronger cultural need to visit the museum. The functional motivation of museum visits was significantly affected by age, occupation, discipline, income, and distance. In the NOMI solution, the quantification of age, occupation, and distance in the Motivation1 and Motivation2 models had similar trends, indicating that the cultural motivation and functional motivation of the Chinese public to visit the museum are complementary in terms of age, occupation, and distance. Members of the public with a multidisciplinary educational background, a monthly income of 3500-20,000, or live 1-3 h away from the museum were less likely to visit the museum for external motivations than others.

Facilitation-based timing was significantly affected by sex, age, occupation, education, discipline, income, and distance. Men were more affected by time facilitation than women when deciding when to visit a museum. The influence of time facilitation on visit timing decreased with age. Of all occupations, civil servants were most affected by the facilitation of time, followed by students and teachers or researchers. Individuals with secondary education were more affected by the convenience of time than others. Overall, an increase in economic income reduced the individual's dependence on time facilitation, but the pattern of economic influence was not entirely monotonous. From the perspective of distance, museum audiences that live 0.5-3 hours away from the museum were less affected by the convenience of time than other spatially distributed publics. Efficiency-based timing was found to be significantly affected by sex, age, occupation, discipline, income, and distance. Individuals that were male, middle-aged, or had a regular job were more concerned with time efficiency than others. People with different discipline backgrounds also differed when deciding upon the timing of a museum visit. Increasing income reduced individuals' dependence on time efficiency. Those living farther away from the museum were less affected.

\section{Discussion}

Under the open for free cultural policy in China, education is the most significant factor affecting whether the public visits a museum, which supports the views of Courty [19], Willekens [62], and Christin [41], and also affects the cultural motivation and facilitation-based timing of museum audiences. Occupation, income, and the spatial relationship between individuals and museums have significant effects on whether individuals visit museums and the pattern of participation of museum audiences, meaning that unequal public cultural services may be caused by industry differences and the geographical location of museums. Income is a very significant factor for cultural participation in museums, and affects all five dimensions of it, which is in line with Poor [63] and Courty [19], but is not in line with Willekens [62]. The disciplinary differentiation of education has also produced differences in museum cultural participation behavior among museum audiences. If cultural capital is used as a criterion for measuring social hierarchy, disciplinary differentiation under the current educational 
practice is likely to cause social hierarchy differentiation. Compared with education, discipline affects more dimensions of cultural participation in museums. Therefore, we propose that academic discipline should be included in the cultural participation model that considers cultural capital as an intermediary effect. Additionally, sex and age have an impact on the cultural participation of the museum. Age affects whether the public visit museums, which is consistent with the findings reported by Courty [19], but sex does not significantly affect whether the public visits a museum, which does not agree with Brida [5], Willekens [62], and Christin [41].

The behavioral pattern of cultural participation in museums of the Chinese public has theoretical value. Firstly, our findings expand upon the cultural participation theory based on regional cultural heterogeneity, by taking the Chinese public as a case study for the cultural participation behavior in museums. Secondly, research on cultural participation in museums belongs to the field of user behavior research, which has value for expanding cultural tourism and museum marketing. Thirdly, the results of our study can explain some problems faced by public management sectors and can provide essential knowledge for the formulation of public cultural policies. Furtherly, our study is also of great significance to studying social equity and how to optimize social equity.

Our findings have many managerial implications, including for the formulation of public cultural policies and the construction of the modern public cultural service system in China. Most obviously, during the formulation of public cultural policies, particular attention should be paid to the education status of the public and the spatial layout of public cultural facilities in the region. The more educated participate more culturally, which is proven in many countries. This indicates that for countries whose cultural policy is supporting by public finance, improving public cultural capital through education is a very necessary way to promote sustainable development by promoting cultural participation. This is not limited to formal school education, because (1) the increasing investment in the school education system cannot educate the public outside of the school (such as urban migrant workers); (2) whether the differences in individual cultural capital caused by disciplinary differentiation can be improved by formal school education is unknown. So, the social education function of public cultural service units such as museums is vital to compensate for the inability of formal school education to benefit the external public. Additionally, the cultural management department should promote the education function of public cultural service institutions through cultural policies to promote overall public education. Moreover, with the development of science and technology, public cultural policies should pay attention to how the cultural sector uses digital technology to reduce the negative impact of geographic space on public cultural participation to more efficiently provide public cultural services. Simultaneously, the function of cultural service facilities as physical public spaces cannot be ignored, so the spatial layout of public cultural facilities should be optimized in the city plan, in combination with urban transportation, land use, and population distribution.

For the construction of a modern public cultural service system in China, the public cultural management department should proactively provide public cultural services to cope with increasing cultural needs [64] and contribute to sustainable cultural development. Active public cultural participation is key to ensuring the sustainable development of culture, and cultural sustainable development is considered important for the construction of national soft power and the maintenance of comprehensive sustainable development. China is in a stage of rapid development and change. In particular, the two-child policy [65], which was officially announced in October 2015 to replace the one-child policy introduced in 1979, will change the population and both the age and sex structure in China. In terms of economics, China is undergoing industrial upgrading, actively promoting the cultural industry as a national pillar industry. Driven by the sharing economy and the creative economy, China will achieve rapid economic development in the future, and the income of individuals will also increase accordingly. China is also increasing investment in education, which will increase the overall cultural capital of society. All these changes will affect cultural participation to varying degrees, including demand, supply, and context. Therefore, when forming cultural policies, cultural 
management departments should change the current passive supply model of public cultural services to a much more active model.

\section{Conclusions}

The purpose of this study was to explore the behavioral pattern of cultural participation in museums for the Chinese public. Firstly, MCA was employed to extract the key features of the museum audience's motivation and timing for visiting the museum and found that the first two key features influencing visit motivation are cultural and functional, and those of timing are facilitation-based and efficiency-based. Secondly, we built models for cultural participation of museums, with cultural capital, economic capital, individual primary attributes, and the spatial relationship between the individual and the museum as independent variables. Finally, using CATREG to analyze the established models using the two ORDI and NOMI solutions, we found that the significance of variables that have a non-monotonic effect on cultural participation behavior is underestimated in the monotonic model. We also found that under the open for free cultural policy in China, education is the most significant factor affecting cultural participation in museums, and occupation, income, distance, discipline, sex, and age also affect different dimensions of cultural participation in museums.

Our research has some limitations. Firstly, discipline, as an independent variable, was missing in the model of whether to visit the museum because the question was only asked in the survey of museum attendees at the Hubei Provincial Museum. Therefore, we could not determine if and how an individual's discipline affects whether they choose to visit a museum. Secondly, social capital is also a potential factor affecting public cultural participation [11,62], but this is difficult measure through questionnaires because it is the sum of the capital of all nodes in a social network, which is not limited to one's parents and their education level, and its active and passive relationship with the peer effect of cultural participation is also uncertain. Therefore, it was not explicitly included in our model. Thirdly, our investigation of occupation lacked an examination of its relevance to cultural creativity, which may have more essential value in studying the impact of cultural and creative industries on social equity [42]. As mentioned earlier, regional culture may cause differences in public behavior, while the sample in this article is regional, so the applicability of the knowledge of cultural participation archived by this study is also limited. Fourthly, from the perspective of psychology, psychological factors, such as attitudes or intentions, may also affect people's behavior. However, we consider that demographic variables should have more reference value for applying research results to policymaking, so we only examined from the perspective of demographic variables mainly, which may lead to an insufficient interpretation of public cultural participation behavior patterns.

Furtherly, the quality of public cultural supply may also affect public perception of cultural participation. However, related studies have mainly focused on the attributes of the demand side, and ignored the investigation of how the quality of supply affects public cultural participation. Future research should explore the pattern of cultural participation from the perspective of supply and demand coordination, by employing supply-side data of public culture services and review data from the Internet.

Author Contributions: W.W. and M.F. designed the experiments and wrote the paper; Q.H. conceived the study; W.W. performed the experiments and analyzed the data. All authors have read and agreed to the published version of the manuscript.

Funding: This research was funded by the National Key R\&D Program of China, grant number 2017YFB1400400.

Acknowledgments: We thank Professor Fu Caiwu and the project team for providing data support and research guidance for this research. Both surveys were conducted by the National Institute of Cultural Development in Wuhan University and conducted in January-February 2018 and January-February 2016, respectively.

Conflicts of Interest: The authors declare no conflict of interest. 


\section{References}

1. Dessein, J.; Soini, K.; Fairclough, G.; Horlings, L. Culture in, for and as Sustainable Development: Conclusions from the COST Action IS1007 Investigating Cultural Sustainability; University of Jyväskylä: Jyväskylä, Finland, 2015.

2. Loach, K.; Rowley, J.; Griffiths, J. Cultural sustainability as a strategy for the survival of museums and libraries. Int. J. Cult. Policy 2016, 23, 186-198. [CrossRef]

3. Soini, K.; Dessein, J. Culture-Sustainability Relation: Towards a Conceptual Framework. Sustainability 2016, 8, 167. [CrossRef]

4. Axelsson, R.; Angelstam, P.; Degerman, E.; Teitelbaum, S.; Andersson, K.; Elbakidze, M.; Drotz, M.K. Social and cultural sustainability: Criteria, indicators, verifier variables for measurement and maps for visualization to support planning. Ambio 2013, 42, 215-228. [CrossRef] [PubMed]

5. Brida, J.G.; Meleddu, M.; Pulina, M. Factors influencing the intention to revisit a cultural attraction: The case study of the Museum of Modern and Contemporary Art in Rovereto. J. Cult. Herit. 2012, 13, 167-174. [CrossRef]

6. Ateca-Amestoy, V.; Prieto-Rodriguez, J. Forecasting accuracy of behavioural models for participation in the arts. Eur. J. Oper. Res. 2013, 229, 124-131. [CrossRef]

7. Kraaykamp, G.; van Gils, W.; Ultee, W. Cultural participation and time restrictions-Explaining the frequency of individual and joint cultural visits. Poetics 2008, 36, 316-332. [CrossRef]

8. Brida, J.G.; Nogare, C.D.; Scuderi, R. Frequency of museum attendance: Motivation matters. J. Cult. Econ. 2016, 40, 261-283. [CrossRef]

9. Van Hek, M.; Kraaykamp, G. How do parents affect cultural participation of their children? Testing hypotheses on the importance of parental example and active parental guidance. Poetics 2015, 52, 124-138. [CrossRef]

10. Willekens, M.; Daenekindt, S.; Lievens, J. Whose Education Matters More? Mothers' and Fathers' Education and the Cultural Participation of Adolescents. Cult. Sociol. 2014, 8, 291-309. [CrossRef]

11. Willekens, M.; Lievens, J. Who participates and how much? Explaining non-attendance and the frequency of attending arts and heritage activities. Poetics 2016, 56, 50-63. [CrossRef]

12. Pol, H.V.D. Measuring Cultural Participation; UNESCO Institute for Statistics: Montreal, QC, Canada, 2012; ISBN 978-92-9189-124-5.

13. Patterson, O. Making Sense of Culture. Annu. Rev. Sociol. 2014, 40, 1-30. [CrossRef]

14. Almond, G.A.; Verba, S. The Civic Culture: Political Attitudes and Democracy in Five Nations; Princeton University Press: Princeton, NJ, USA, 1963.

15. Eliasoph, N.; Lichterman, P. Culture in Interaction. Am. J. Sociol. 2003, 108, 735-794. [CrossRef]

16. Anderson, K.; Domosh, M.; Pile, S.; Thrift, N. Handbook of Cultural Geography; SAGE: London, UK, 2003; pp. 2-6. ISBN 978-0761969259.

17. Shani, G. How place shapes taste: The local formation of middle-class residential preferences in two Israeli cities. J. Consum. Cult. 2019. [CrossRef]

18. Han, S.Y.; Tsou, M.H.; Clarke, K.C. Revisiting the death of geography in the era of Big Data: The friction of distance in cyberspace and real space. Int. J. Digit. Earth 2017, 11, 451-469. [CrossRef]

19. Courty, P.; Zhang, F. Cultural participation in major Chinese cities. J. Cult. Econ. 2018, 42, 543-592. [CrossRef]

20. Chen, H. Issues and Methods for Museum Audience Research. Chin. Mus. 1986, 3, $62-65$.

21. Shan, J. Museum Management in the Age of Service. Dunhuang Res. 2013, 33, 31-39.

22. Kang, Y. An Analysis of the Behavior and Requirement of Elder Visitors in The Capital Museum. Southeast Cult. 2011, 15, 88-92.

23. Lv, J.; Xu, H.; Yu, X.; Wu, K. Investigation Report of Audience Behaviour of Hubei Provincial Museum. Southeast Cult. 2012, 28, 115-122.

24. Sheng, C.; Chen, M. A study of experience expectations of museum visitors. Tour. Manag. 2012, 33, 53-60. [CrossRef]

25. Yin, K. Museum Visitor Study: Concept, Theory and Practice. Southeast Cult. 2015, 31, 112-118.

26. Jian, O. On China's Museum Free Policy: In the View of Public Goods. Chin. Public Adm. 2008, 24, 41-43.

27. Lu, J.; Li, Y. Situations, Problems and Countermeasures: A Study On Exhibition, Education and Public Services of Museum. Southeast Cult. 2011, 1, 9-15. 
28. Fu, C.; Xu, Q. Efficiency Dilemma of Grassroots Cultural Units: Structural Problems of the Supply Front or Management Technology Problems?-Observation on Ten Cultural Stations in Five Provinces. J. Shandong Univ. (Philos. Soc. Sci.) 2017, 67, 50-59.

29. Fu, C.; Yue, N. Restrictions on Incremental Financial Investment in the Construction of Modern Public Cultural Service System: Based on Investigations of County Public Libraries. J. Libr. Sci. China 2018, 44, 19-39.

30. Fu, C.; Zhang, W. A Study on Efficiency, Return to Scale and "Congestion" of Provincial Public Libraries in China. China Soft Sci. 2017, 32, 72-81.

31. Fu, C.; Zhang, W. Research on the Total Factor Productivity of the Public Library Industry in China-Analysis of DEA-malmquist Model Based on Provincial Panel Data. J. Cent. China Norm. Univ. (Humanit. Soc. Sci.) 2018, 57, 81-89.

32. Duxbury, N.; Kangas, A.; De Beukelaer, C. Cultural policies for sustainable development: Four strategic paths. Int. J. Cult. Policy 2017, 23, 214-230. [CrossRef]

33. Belfiore, E.; Gibson, L. Histories of Cultural Participation, Values and Governance; Palgrave Macmillan: London, UK, 2019; ISBN 978-1-137-55026-2.

34. Bourdieu, P. Distinction: A Social Critique of the Judgement of Taste; Harvard University Press: Cambridge, MA, USA, 1984.

35. Bourdieu, P. The Forms of Capital. In Readings in Economic Sociology; Blackwell Publishers Ltd.: Oxford, UK, 2002; pp. 280-291.

36. Kim, Y.K.; Sax, L.J. Are the Effects of Student-Faculty Interaction Dependent on Academic Major? An Examination Using Multilevel Modeling. Res. High. Educ. 2011, 52, 589-615. [CrossRef]

37. Maslow, A.H. A theory of human motivation. Psychol. Rev. 1943, 50, 370-396. [CrossRef]

38. Molinillo, S.; Japutra, A. Factors influencing domestic tourist attendance at cultural attractions in Andalusia, Spain. J. Destin. Mark. Manag. 2017, 6, 456-464. [CrossRef]

39. Kim, H.; Cheng, C.-K.; O'Leary, J.T. Understanding participation patterns and trends in tourism cultural attractions. Tour. Manag. 2007, 28, 1366-1371. [CrossRef]

40. Matthews, W.J.; Meck, W.H. Temporal cognition: Connecting subjective time to perception, attention, and memory. Psychol. Bull. 2016, 142, 865-907. [CrossRef]

41. Christin, A. Sex and highbrow cultural participation in the United States. Poetics 2012, 40, 423-443. [CrossRef]

42. Campbell, P.; O'Brien, D.; Taylor, M. Cultural Engagement and the Economic Performance of the Cultural and Creative Industries: An Occupational Critique. Sociology 2018, 53, 347-367. [CrossRef]

43. Roux, B.L.; Rouanet, H. Multiple Correspondence Analysis; SAGE: Thousand Oaks, CA, USA, 2010; pp. 2-3. ISBN 978-1-4129-6897-3.

44. DiMaggio, P.; Mukhtar, T. Arts participation as cultural capital in the United States, 1982-2002: Signs of decline? Poetics 2004, 32, 169-194. [CrossRef]

45. Glorieux, I.; Kuppens, T.; Vandebroeck, D. Mind the gap: Societal limits to public library effectiveness. Libr. Inf. Sci. Res. 2007, 29, 188-208. [CrossRef]

46. Walker, C.; Scott-Melnyk, S. Reggae to Rachmaninoff: How and Why People Participate in Arts and Culture. Building Arts Participation. New Findings from the Field; Urban Inst.: Washington, DC, USA, 2002.

47. D'Angelo, F.; Furia, D.; Crociata, A.; Castagna, A. Education and culture: Evidence from live performing arts in Italy. Procedia Soc. Behav. Sci. 2010, 1373-1378. [CrossRef]

48. Fu, C.; Hou, X. Impact of Cultural Capital upon Residents Cultural Consumption Behavior: Basedupon a Comparison between Online and Offline Cultural Consumer Groups. Hundred Sch. Arts 2017, 33, $39-46$.

49. Upright, C.B. Social capital and cultural participation: Spousal influences on attendance at arts events. Poetics 2004, 32, 129-143. [CrossRef]

50. Brook, O. Spatial equity and cultural participation: How access influences attendance at museums and galleries in London. Cult. Trends 2016, 25, 21-34. [CrossRef]

51. Meulman, J.J.; Heiser, W.J. Categorical Regression (CATREG). In SPSS Categories ${ }^{\circledR}$ 14.0; SPSS Inc.: Chicago, IL, USA, 2005; pp. 19-28.

52. Meulman, J.J. Optimal Scaling Methods for Multivariate Categorical Data Analysis; SPSS Inc.: Chicago, IL, USA, 1998.

53. Breiman, L.; Friedman, J.H. Estimating Optimal Transformations for Multiple Regression and Correlation. J. Am. Stat. Assoc. 1985, 80, 580-598. [CrossRef] 
54. Hartmann, A.; Van der Kooij, A.J.; Zeeck, A. Exploring nonlinear relations: Models of clinical decision making by regression with optimal scaling. Psychother. Res. 2009, 19, 482-492. [CrossRef]

55. Salvatore, S.; Tschacher, W. Time dependency of psychotherapeutic exchanges: The contribution of the Theory of Dynamic Systems in analyzing process. Front. Psychol. 2012, 3, 14. [CrossRef]

56. Almeida, A.; Garrod, B.A. CATREG model of destination choice for a mature Island destination. J. Destin. Mark. Manag. 2018, 8, 32-40. [CrossRef]

57. Herzberg, F. One more time: How do you motivate employees. Harv. Bus. Rev. 1987, 65, 109-120.

58. Ryan, R.M.; Deci, E.L. Intrinsic and Extrinsic Motivations: Classic Definitions and New Directions. Contemp. Educ. Psychol. 2000, 25, 54-67. [CrossRef]

59. Zolait, A.H.S. The nature and components of perceived behavioural control as an element of theory of planned behaviour. Behav. Inf. Technol. 2011, 33, 65-85. [CrossRef]

60. Ajzen, I. The Theory of Planned Behavior. Organ. Behav. Hum. Decis. Process. 1991, 50, 179-211. [CrossRef]

61. Notani, A. Moderators of Perceived Behavioral Control's Predictiveness in the Theory of Planned Behavior: A Meta-Analysis. J. Consum. Psychol. 1998, 7, 247-271. [CrossRef]

62. Willekens, M.; Lievens, J. Family (and) culture: The effect of cultural capital within the family on the cultural participation of adolescents. Poetics 2014, 42, 98-113. [CrossRef]

63. Poor, P.J.; Smith, J.M. Travel Cost Analysis of a Cultural Heritage Site: The Case of Historic St. Mary's City of Maryland. J. Cult. Econ. 2004, 28, 217-229. [CrossRef]

64. Thaler, R.H.; Sunstein, C.R. Nudge: Improving Decisions about Health, Wealth, and Happiness; Penguin: London, UK, 2009.

65. Zeng, Y.; Hesketh, T. The effects of China's universal two-child policy. Lancet 2016, 388, 1930-1938. [CrossRef]

(C) 2020 by the authors. Licensee MDPI, Basel, Switzerland. This article is an open access article distributed under the terms and conditions of the Creative Commons Attribution (CC BY) license (http://creativecommons.org/licenses/by/4.0/). 